\title{
A DATA MODEL FOR CARBON FOOTPRINT SIMULATION IN CONSUMER GOODS SUPPLY CHAINS
}

\author{
Kai Gutenschwager \\ Ostfalia University of Applied Sciences \\ Am Exer 2 \\ 38302 Wolfenbüttel, GERMANY
}

\author{
Markus Rabe \\ Mehmet Umut Sari \\ Technical University Dortmund \\ Leonhard-Euler-Str. 5 \\ 44227 Dortmund, GERMANY
}

Till Fechteler

SimPlan AG

Adolfstraße 21

38102 Braunschweig, GERMANY

\begin{abstract}
$\mathrm{CO}_{2}$ efficiency is currently a popular topic in supply chain management. Most approaches are based on the Life Cycle Assessment (LCA) which usually exploits data from a static database. This approach is effective when estimating the carbon footprint of products or groups of products in general. Simulation has been a proper method for metering the effectiveness of logistics systems, and could thus be expected to also support the analysis of $\mathrm{CO}_{2}$ efficiency in supply chains (SC) when combined with an LCA database. However, research shows that this combination does not deliver reliable results when the target of the study is improvement of the logistics in the SC. The paper demonstrates the shortcomings of the LCAanalogous approach and proposes a data model that enables discrete event simulation of SC logistics including its impact on the carbon footprint that is under development in the e-SAVE joint project funded by the European Commission.
\end{abstract}

\section{INTRODUCTION}

Globalization of Manufacturing and Distribution has brought up the new discipline of Supply Chain Management (SCM), targeting to handle all aspects of the planning and operation of the supply chains (SC), which are frequently even forming complex supply networks. As a parallel development, the use of resources (renewable or not) has come into focus together with all other impacts of the manufacturing process on the environment and the human being. This approach has led to intense work on the so called Life Cycle Analysis (LCA) that aims to calculate the total impact of a product or service from cradle to grave.

LCA follows a growing consumer request to purchase "green" and "responsible" products or services, with the expectation to contribute e.g., to a lower emission of green house gas. Samples for product LCA can be found from relatively simple products like Linoleum floors (Gorree et al. 2000) to highly complex ones like Daimler's S-Class in 2006 (Finkbeiner et al. 2006).

SCM, on the other hand, usually puts the focus on a specific section of the life cycle, such as the distribution of products or the delivery of parts in the supply section that is controlled by the enterprise itself.

For this paper, we selected the system boundary as the distribution chain from the sales-ready packaged product until the retailer shop, only taking into account the emission of $\mathrm{CO}_{2}$ equivalents, and assum- 


\section{Rabe, Gutenschwager, Fechteler, and Sari}

ing that no mixed pallets (several products on the same pallet) are handled. This includes the electrical power consumption, according to scope 2 of the Greenhouse Gas Protocol (in this paper, we will not discuss the conversion of measured values into $\mathrm{CO}_{2}$ equivalents). Thus, neither the impact of manufacturing is considered (in terms of materials or processes) nor the impact of the use of the product. From the view of a manufacturing company, the SC is not the most important, but an interesting part of the chain, both in terms of cost and emissions. Emissions are usually broken down by categories like product group, region, or customer. This is due to the fact that the first target is not information to the customer, but optimization of the SC, i.e. reduction of cost and carbon footprint. In addition, results per product might also be interesting to contribute to an overall LCA project with respect to the footprint of the SC.

Following this target, it is inevitable to study the impact of logistic changes on costs and emissions. Thus, it seems appealing to enrich the logistics simulation model by features for measuring $\mathrm{CO}_{2}$-related data by utilizing information from the available LCA databases. However, a more narrow investigation demonstrates that due to the required high aggregation level necessary for the LCA, the usual LCA figures are not necessarily suitable for simulation. To illustrate this with an example, a typical LCA figure used to calculate the $\mathrm{CO}_{2}$ impact of a transport is to define a parameter for $\mathrm{CO}_{2}$ per ton and kilometer, which is perfect for an LCA that cannot investigate aspects like the utilization of trucks. However, if this factor is applied to the transports in a simulation model, it becomes obvious that a dramatic improvement like changing the utilization of a truck from $40 \%$ to $80 \%$ correlated with a $50 \%$ cut of the running trucks will not show any effect in the outcome, as the tons transported per kilometer remain unchanged. Therefore, the target of this paper is to discuss, which calculation mechanisms are suitable for studying the impact of logistics scenarios on the $\mathrm{CO}_{2}$ emission. In order to efficiently study this kind of models, we assume a data-driven model generation as proposed for manufacturing purposes by Rabe and Gochev (2006). Thus, the major research is on designing a suitable data model, considering permanent and temporary data objects, for this purpose.

This paper roots from research conducted in the e-SAVE project which is operated by a European consortium with financial contribution from the European Commission. This project, targeting the monitoring and simulation of distribution supply chains in the Fast Moving Consumer Goods (FMCG) industry, has started in January 2012 and will last until June 2014. The work presented here covers the results of the first project year, and is restricted to the simulation aspect of the e-SAVE project.

This paper is organized as follows. After a short summary of the underlying scientific methods (Chapter 2) and existing commercial tools that at least partially follow the needs motivated above (Section 3), the requirements on a data model for carbon footprint simulation in the FMCG distribution supply chain are derived (Section 4). An approach towards a data model is developed following these requirements (Section 5). The paper concludes with the results achieved so far and an outlook on further research (Section 6).

\section{SUMMARY OF UNDERLYING METHODS}

As a prerequisite to make the SC greener, we have to collect, choose and analyze the data that influence the green strategy. Life cycle assessment (LCA) is recognized as reliable by many stakeholders, because it is based on international trusted databases like ecoinvent or the European Reference Life Cycle Database (cp. Cirullies et al.2012). Referring to the definition of the International Organization for Standardization (ISO), Life Cycle Assessment is "Compilation and evaluation of the inputs, outputs and the potential environmental impacts of a product system throughout its life cycle" (ISO 2009a). LCA is an effective tool for the analysis of the environmental burden of products at all stages of their life cycle.

Green Supply Chains are discussed in many publications, but from quite different perspectives. An overview, with a specific focus on simulation aspects, can be found in (Rabe and Deininger 2011), covering the green design, production, logistics, packaging and recycling (cp. Gao et al. 2009), selection of green suppliers (cp. Che 2010), Gaining green certification such as ISO 14001 (ISO 2009b), WEEE (European Parliament 2003a), or RoHS (European Parliament 2003b). 


\section{Rabe, Gutenschwager, Fechteler, and Sari}

Only a limited number of researchers are discussing Simulation in the context of $\mathrm{CO}_{2}$ assessment. Kuhl and Zhou have presented a sustainability toolkit for simulation (Kuhl and Zhou 2010). This toolkit is, however, quite generic. It provides all basic mechanisms to assess the carbon emission in the same way as any other performance indicator, but it does not support the process of footprint calculation itself.

An application developed by Widok et al. (2012) combines LCA and discrete event simulation (DES). They aim to extend the horizon in material flow analysis and to generate a special Environmental Management Information System (EMIS). The intention of the application is "not only on economic optimization but also on material flow analysis with a possible integration of social criteria". Cirullies et al. (2012) have elaborated requirements to extend the SC simulation tool called OTD-NET with green KPIs to get the possibility to take decisions by regarding environmental aspects. A state of the art analysis by Andersson et al. (2012) compiles six case studies from 2007 and forward in respect of the integration of LCA in the DES to reduce energy consumption, especially in the production. They found that it is possible to get advantages with DES in performing sustainability analysis, but also note three main problems:

- "Vague problem formulation resulting in unnecessarily extensive and expensive not answering the correct question.

- Non-standardized verification and validation procedures resulting in unreliable results inappropriate for comparisons and benchmarking.

- Data management is expensive, showing the importance of well-structured and limitative methods."

Lindskog et al. (2011) have compared the DES method with the Simplified Life Cycle Assesment (SLCA) method concerning data management, determination of environmental footprint and communication of the results, on the same production system. The DES method has created more detailed parameters than the SLCA method. The assignment of the respective method lies in the goal. If the product's environmental footprint is focused, the SLCA method has to be preferred because it takes in this case less time than the DES method. "But if a simulation model already exists or the purpose is to evaluate and improve the system" the DES method has to be suggested". Boulonne et al. (2011) have developed a software solution called the RIM solution. It should help to "facilitate data sharing between data sources and DES model". The solution gives the ability to store sustainability indicators. Considering the indicators it is in an elementary level. Regarding the standardization problem (cp. Andersson et al. 2012) it gives a first approach.

\section{SUMMARY OF COMMERCIAL TOOLS}

In this section, we give an overview of tools for $\mathrm{SC}$ simulation with a focus on $\mathrm{CO}_{2}$ attributes. There are several vendors of DES tools which originated from the field of intra-logistic systems. Some of those tools offer the possibility to simulate supply chains, mostly by providing specific elements within class libraries to model the main aspects of supply chains, e.g. transport relations and order policies. Examples are Anylogic (XJ Technologies), Arena (Rockwell Automation), Enterprise Dynamics (Incontrol), FlexSim (FlexSim Software Products), Tecnomatix Plant Simulation (Siemens), Witness (Lanner Simulation Technology), etc. These tools do not offer a specific database approach for defining SCs and respective key figure systems. Instead, most of these tools concentrate on object-oriented modeling techniques, where each model object e.g., a distribution center, needs to be parameterized within the modeling environment. For importing data, the standard interfaces of spreadsheet applications and database systems can be used in most tools. However, for such imports some programming effort needs to be taken into account. To our knowledge, only Plant Simulation offers CO2-relevant KPIs as standard statistics.

A discrete event simulation tool especially designed for SC simulation is the IBM Supply Chain Analyzer. The concept is also to provide a class library (for the discrete event simulation tool SIMPROCESS) with highly aggregated SC elements. The tool has been developed from 1992 on and has been used in several IBM internal projects since, see Bagchi et al. (1998) and Archibald et al. (1999). The simulation library comprises, similar to other libraries, a set of classes like Customer (to generate orders as a stochastic variable), Manufacturing, Distribution (warehouses and outlets), Transportation, Inventory Planning, 


\section{Rabe, Gutenschwager, Fechteler, and Sari}

Forecasting and Supply Planning (to model different planning and order strategies). Supply Net Simulator (SNS) is another tool especially designed for SC simulation by Daimler (cp. Baumgärtel et al. 2007). However, both SNS and IBM Supply Chain Analyzer do not consider $\mathrm{CO}_{2}$-relevent aspects.

On the other hand there are some more "general" tools for SC modeling and analysis, usually originating in the field of analytical models and optimization. Here, 4flow vista is an example of tools which offer the possibility to define supply chains and perform the analysis of different scenarios. The optimization components usually deal with classical OR problems for SC design, like the facility location problem or covering locations problems. Even though these tools comprise a great variety of data objects, which allow a rather detailed level of modeling, the focus is on aggregating the data to a schema needed for the mentioned optimization models. Thus, processes are not modeled in detail. 4 flow vista, e.g., offers a detailed analysis of $\mathrm{CO}_{2}$ emissions, however on a static level, neglecting the actual process of transport (cp. e.g., Gross et al. 2012). Accordingly, no DES component is given for this tool.

The Logistics Designer (LOCOM) and the Supply Chain Guru (Llamasoft) also originate in classic optimization tools for SCs, but offer DES components for the analysis of the dynamic behavior of SCss including the possibility to gain insight on $\mathrm{CO}_{2}$ emissions. For the analysis of $\mathrm{CO}_{2}$ emissions the factors given in the Handbook Emission Factors for Road Transport (HBEFA, cp. Hausberger et al. 2009) are integrated in the Logistics Designer, which allows differentiated factors for different means of transport and different utilization ratios. However, a detailed description of the implementation and evaluation of $\mathrm{CO}_{2}$ relevant factors within the simulation components have not been published for either tool.

SimChain is a DES tool, which has originally been developed as a class library for the simulation tool Plant Simulation under the name ICON-SimChain (cp. Alicke and Gutenschwager 2004). The data basis has originally been modeled using Plant Simulation's internal data structures, but later been changed to a mySQL database. The database is used to automatically generate the simulation model utilizing a SimChain-specific building block library, to feed the running model with operational data like orders, and to store the result data. For accessing the data, a separate GUI component is provided, while the simulation component is still Plant Simulation. Here, an interface has been implemented to read the data from the database and automatically generate the model for the respective scenario. After each simulation run the results are pre-evaluated and stored in the database (Fig. 1).

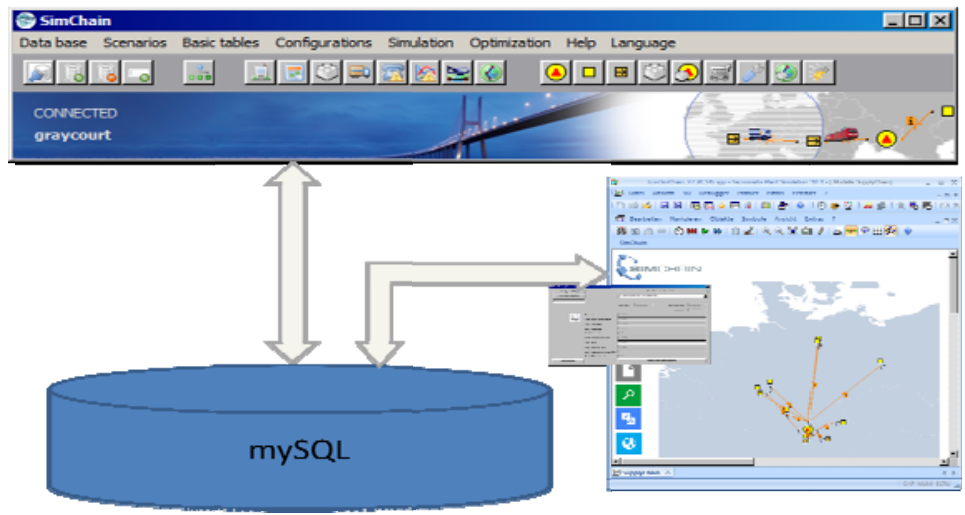

Figure 1: Basic architecture of SimChain.

The data model of SimChain consists of more than 60 tables. It allows the modeling of a great variety of processes within SC modeling. Here, different nodes are distinguished in the simulation component, namely customers, sites, hubs, and plain suppliers. The nodes are connected by transport relations. Sourcing routes are defined as sequences of transport relations (including a given number of hubs) to model multi-modal delivery strategies. Due to its flexible, data-driven structure SimChain has been chosen as a basis for the data model described in this paper. 
Rabe, Gutenschwager, Fechteler, and Sari

\section{REQUIREMENTS}

The goal of our research is to meter the $\mathrm{CO}_{2}$ emission caused by the SC in an adequate accuracy and to gain suitable performance indicators that allow an optimization of the SC under consideration. The optimization target is to reduce the emission without unacceptable losses in terms of cost or service levels provided. The first step is to identify where the $\mathrm{CO}_{2}$ emission does come from. For this purpose, we use the functional modeling approach (cp. the German original by Wieneke-Toutaoui 1987 or the English summary in Seliger et al. 1987) that defines the following five generic functions:

- manufacture, including all types of process that is changing the SKU

- assembly, defining all merges and separations of material,

- test, especially enabling conditional paths and repair loops,

- transport, and

- store.

Because the functional approach systematically denominates the activity with a verb, this paper consistently uses the terms "store" (not: "storage") and "transport" when functions are addressed. With the assumptions given in the introduction, we assume that transport and store will be the most relevant functions in the SC under consideration. In general, however, additional activities like promotion packaging might be of interest. Such an activity can have a rather complex functionality, as it might require the bundling of products ("assembly") or processes like foil sealing ("manufacture").

In the next step we have to understand the relationship between the logical functions and the physical equipment. In our SC we will find means of transport like trucks, trains, and ships as well as distribution centers being mainly warehouses. On a detailed view, both categories will provide both functions:

- Distribution centers store products but also provide transport between the loading zones and the storage zones.

- Transports will always imply to store the material on the means of transport.

Analyzing the distribution center in more detail, we can learn from measurements that the major emission is caused by providing a given temperature range for storage, followed by lighting and (if necessary) heating or cooling of the transporting zone. The energy implied by the transport is relatively low. On the other hand, a detailed model of the transport within the warehouses would initiate a huge effort and performance loss of a simulation model. Therefore, we assume that we can add the total $\mathrm{CO}_{2}$ impact of all transports within the warehouse to the $\mathrm{CO}_{2}$ impact of the store function, and then neglect the detailed transport functions of the warehouse.

However, understanding that a major impact comes from keeping temperature ranges, this part should be further investigated. Especially in the FMCG sector, there are typically zones in the warehouse with different temperature levels e.g., for frozen goods, vegetables (near to zero) or just dry storage. As we can expect a significant impact from this, we will need to respect such zones in our simulation approach.

Analyzing the transport, we obviously have to differentiate means of transport like e.g., trains, trucks, ships, or aircrafts. However, we also have to consider multi-mode transports like going by truck to a railway cargo hub, then a long distance by train, and the last miles again by truck. Such activities (in LCA referred to as allocation problem) will also include merges and split-ups, if e.g., a truck takes a set of pallets to a hub which then go in different directions by train. Therefore, we will need to differentiate routes (from source to destination of the supply) from transports (by a specific means between two points), and allow for defining routes as a combination of transports.

Analogous to the warehouse, the transported goods often require given temperature ranges. Thus, for transport we should obviously differentiate between the transport (emission caused "by moving") and store (emission caused "by time"). Our simulation approach will thus require to handle both aspects.

Having detected the sources of emission and defined how to handle them, a total $\mathrm{CO}_{2}$ (equivalent) emission can be calculated. This is, however, not sufficient, as it will only give some kind of benchmark, not allowing for improving the SC in detail. For such an optimization, disaggregated KPIs will be needed. 


\section{Rabe, Gutenschwager, Fechteler, and Sari}

A first idea could be to differentiate just by the elements of the SC like transports and warehouses. This is obviously easy, as it requires to record the $\mathrm{CO}_{2}$ at its (simulated) source and just required a suitable counter per element (in case of warehouses, the elements might be the zones, not the complete warehouse). However, such mechanism will allow only for a very restricted interpretation.

The basic step for disaggregation is to consider emission per stock keeping unit (SKU). This will require respective counters for all SKUs (e.g., a specific kind of bread under a given brand), which should not be a hard problem to solve. But, we face the challenge to allocate the emission of a store or transport function to the (mixed) set of SKUs which are the objects of the function.

However, experience shows that a categorization just by SKU will not be sufficient. On the one hand side it might deliver unnecessary details, as the SCs for very similar products will be designed in the same way. Such key figures could easily be aggregated from the SKU measures. But, a further differentiation is required, typically by customers regions, etc. All of these differentiated figures cannot be gained from the SKU figures. Even worse, it can be recognized that this information is not even bound to a specific instance of an SKU: A pallet on transport to an (intermediate) distribution center does not necessarily "know" its final region or customer. Discussions in the e-SAVE project have shown that such requirements lead to the necessity to follow the $\mathrm{CO}_{2}$ impact for each transported pallet of an SKU. This is a special challenge to the simulation data model, taking into account the huge number of movable objects that we find in a SC over a typical observation period.

Furthermore, a mechanism that would really follow up the impact of each movable object will not only go along with a rather bad performance, but might also provide useless results. Take the sample of two pallets of frozen goods in the same distribution center: One of them has just arrived yesterday, the other one is already in storage for 3 weeks. With a pallet-per-pallet approach, the latter one will have accumulated significantly more $\mathrm{CO}_{2}$ emission, as it has been "charged" for additional three weeks of cooling. Now, if both pallets are delivered to two different stores, they will receive goods with different $\mathrm{CO}_{2}$ impact that are else wise identical. Even worse, the result may just depend on the (logistically irrelevant) selection. For example, a time difference of a few minutes in ordering the goods might change the dedication of the pallets and thus just revert the emission result. In terms of logistics optimization to lower the $\mathrm{CO}_{2}$ impact, such kind of result will not be helpful.

Therefore, we need to define a simulation model that respects the store and transport functions given by transport means and warehouses and defines a practical, adequately accurate, and useful approach to calculate different KPI of the FMCG distribution supply chain. This approach can be seen as an analogous method to activity-based costing (cp. Miller and Vollman 1985).

\section{DERIVATION OF THE SIMULATION DATA MODEL}

\subsection{Describing $\mathrm{CO}_{2}$ Equivalent Sources}

As described above, in this paper the consideration of $\mathrm{CO}_{2}$ emission is restricted to transport means and warehouses. The challenge is to define applicable and suitably accurate mechanisms to calculate the emission during the simulation run. For a systematic approach, the functional model is used as described above. For the store function, $\mathrm{CO}_{2}$ impact is a function of time. As a simplification, we assume that the consumption is constant $\left(\mathrm{CO}_{2}\right.$ per hour). For the transport function, $\mathrm{CO}_{2}$ impact is a function of movement, i.e. in a first approximation of the distance and the $\mathrm{CO}_{2}$ emission per kilometer. While good procedures exist to estimate the travel distance, the second figure raises more problems, as it will depend e.g., on the topography, traffic, weight, and also on the driver's behavior. Traffic and topography are implicitly modeled, as we also consider the traveling time (as discrete distributions), but they are not used as influence factor on the emission with respect to the transport function, as they would require an even more detailed transport model that is not suitable for the goals of our studies. Thus, weight is left as an indicator. Taking into account that the driver's behavior can have more impact than the actual load of the truck, a too sophisticated model does not seem productive. In the e-SAVE project, partners have decided to de- 
termine two figures, namely the $\mathrm{CO}_{2}$ emission of empty vehicles ETE and of fully loaded vehicles ETF, specified for a user-defined set of transport means. This approach would allow for defining any function of emission(load), but the project currently only differentiates empty and loaded (i.e., at least one pallet).

The mechanisms described are not applicable for "less than a truck" loads, where 3PL providers arrange mixed transports with other (from the systems viewpoint "unknown") customers. This is logical, as in such cases the part of the system that would require the logistics optimization is per definition outside of the model. Therefore, such kind of transports still has to be handled by a "ton km" model - which is correct, as long as no optimization is intended here.

Now, we have to assign the functions to the devices, starting with the warehouse. We assume the warehouse has $z$ zones with (potentially) different temperatures. The emission is set to a constant value $E W Z(z)$ measured in $\mathrm{kg} / \mathrm{h}$. In addition, there will be emissions that are not directly related to the zones e.g., lighting outside the zones, or forklift loading. which we will take as a constant overhead figure $E W O$.

Transports will be illustrated by trucks here, but the calculation is the same for any other means of transport. Trucks can be roughly be categorized by maximum volume and transport weight as well as the temperature zone(s) that they can provide. The selection of the correct means of transport is a logistical decision (based e.g., on total number of pallets to be transported, distance, cost, time etc.). Therefore, in this paper we assume the correct selection as a prerequisite and focus on the emission parameters. Like in the warehouse zones, we can find the cooling impact as a constant $E T Z(z)$. In most cases, there will be only one zone, but the general case does not raise any additional problems and might have relevance, e.g. on vessels. In addition, we might consider a constant ETO as in the warehouse case, which also applies only for large transport systems.

These amounts add on the emission caused by the movement. With the assumptions above, when transporting pallets over a distance $d$ we will always assume a non-empty truck - no pallets would initiate no movement and the added emission is $d E T F$. Also, we have to return the truck to its source (or any other suitable source for the next transport). Assuming our own fleet, this would cause an added emission of $d$ ETE. However, at least with 3PL this assumption will be unrealistic, as the return path is not to the origin, but to another (unknown) source of transport for another party. Thus, we propose to introduce an empty-load percentage $P T E$ to represent that only a part of the empty run back should be assigned to our system, leading to a term $d$ ETE PTE. The total emission of the system under consideration is obviously simply the total of all the figures given above.

\section{2 $\quad \mathrm{CO}_{2}$ Assignment to Objects}

Things become more sophisticated when we try to assign the emission to the model objects. As justified above, we need a method to assign emission to pallets. Any allocation of emission to single elements will require the calculation of a distribution ratio. The four mostly considered ratios are per number of SKUs, per volume, per net weight, or per gross weight. The best selection can highly depend on the situation, and there could be even reasons for highly complex assumptions. For illustration, a truck's load could be limited either by volume (light goods) or by gross weight (heavy goods). Thus, it might be reasonable to select the ratio based on the actual load. Obviously, this selection does not raise specific problems, and the simulation might just foresee a parameter to choose the selected ratio per element. Therefore, we will not further discuss this decision and, for conciseness, assume assign by the number of SKUs.

Starting again with the store function, we need to allocate the emission (which we assumed to be constant over time) to the SKUs. Following the ratio selected above, an ideal approach could be to integrate the area under the filling curve of a zone, leading to a mean utilization per hour $M U H$ at the end of the simulation, and then calculate the specific emission related to our $n$ pallets over a time $t$ as

$$
E W(S K U)=\operatorname{tn}(S K U) E W Z(z) / M U H
$$

However, this procedure has the clear disadvantage that it will require a post calculation (MUH will not be known before the end of the simulation run) and thus a storage or tracing of all single events, critical for the performance of the simulation model. Therefore, we need an approach that does not require "fu- 


\section{Rabe, Gutenschwager, Fechteler, and Sari}

ture" knowledge but still leads to the correct total. In order to achieve this, we take a measurement at any time when the load of a store function changes. This will happen at warehouses when trucks arrive or depart, and for trucks just at the beginning and end of the transport. At this time, we calculate the time $t$ that has passed since the last change, and then we calculate $E W$ for all SKUs according to the equation

$$
E W(S K U)=t \frac{n(S K U)}{N}\left(E W Z(z)+\frac{E W O A P(z)}{T A P}\right)
$$

where $N$ is the total number of pallets stored in time $t$. The disadvantage of this approach is that it is not robust against an empty storage. This seems, however, not critical. For warehouses in the business that we are addressing, this situation will never occur except in very special situations. For trucks, we have already differentiated the empty state from the "full" state defined as a minimum of $N>0$ pallets. As the final step of the store function, we have to care for the EWO term. Here, too sophisticated mechanisms for assignment appear not adequate, as there is a clear risk of introducing false effects. Therefore, we propose to use the ratio of available places $A P(z)$ per zone, which sum up to the total available places $T A P$ of the warehouse. As defined above, this formula applies also to trucks, with the open problem of empty truck runs with $N=0$. For simplification, we currently assume that for an empty transport means $E W Z=E W O=0$, i.e. that any cooling is switched off on empty runs. This is, of course, a quite rigid assumption and further research is required to understand its implication and potential alternative procedures.

Unfortunately, the adequate allocation for the transport function appears to be more sophisticated than of store. In a rather simple approach, we could just use the same principle, i.e.

$$
E T(S K U)=d n(S K U) /{ }_{N}(E T F+E T E P T E)
$$

respecting the percentage of empty-run allocation. However, this equation still assumes a simple sourceto-sink transport. In reality, we can identify at least four major delivery procedures:

- Simple source to sink as above

- Multi-drop delivery on short distance (e.g. from the distribution center to the nearby shops)

- Multi-drop delivery on long distance (typically, a long-distance drive and then multiple stops)

- Milk-run (given route used independently of the actual load)

In all cases except the first one we need to define more detailed rules for the $\mathrm{CO}_{2}$ assignment. A naïve approach could apply the formulae above just for each single transport relation (each section of the transport). However, this approach clearly delivers unrealistic results, which can be most easily recognized at the milk-run case. Obviously, all goods in the first sectors experience a relatively low $\mathrm{CO}_{2}$ assignments (many goods on truck), while at the end of the run the few remaining pallets face the full impact. The problem becomes clear when we just revert the direction of the milk run: Now the pallets facing the most emission before are the "winners" and generate only a few emission.

Currently, this problem is solved with the following approach: We propose not to differentiate the pallets by destination, but to calculate the full emission of the truck as indicated before (including the empty run, if applicable) and then apply the ratio for all transported pallets. This will, however, lead to inadequate results in some cases, e.g. in case of multi-drop with very long distance between the last drops. Therefore, we assume that further research is required here.

\subsection{Object Aggregation}

With the equations above, we can factually assign $\mathrm{CO}_{2}$ equivalents to pallets. This procedure enables us to see the " $\mathrm{CO}_{2}$ load" of a pallet growing during its way through the system. Finally, when the pallet passes the simulation sink, we can add the accumulated $\mathrm{CO}_{2}$ equivalent to any counters required by the application (counters per SKU, per product category, per customer, per country of destination, per country of source, etc.). However, this assignment of $\mathrm{CO}_{2}$ to the specific pallet has two disadvantages. First, it requires real counters in the simulation model per active pallet, i.e. an object must be generated and kept all the time from the source to the sink, for each single pallet. This will require a huge amount of computer 


\section{Rabe, Gutenschwager, Fechteler, and Sari}

storage and, therefore, significantly slow down the model execution. Second, this procedure leads to an "accuracy" that might provide misleading results, as already described in Section 4 on the sample of two pallets with frozen goods. Therefore, this requirement has to be respected, and a mechanism needs to be developed that avoids unrealistic calculations. In our application case, we need to ensure that the $\mathrm{CO}_{2} \mathrm{im}$ pact of goods taken from a warehouse does not depend on which instance of (equal) goods we select. In consequence, we propose a procedure to unify the $\mathrm{CO}_{2}$ impact of equal goods. As we will see, this procedure has the very positive side effect that we can save a significant portion of the computer storage.

The assumption is that for any store function we keep a record for each SKU currently stored with the current number of SKU instances and the total accumulated emission $T A E(S K U)$. Thus, the model keeps the emission per SKU, not per instance. How does this change the calculation mechanisms?

First, the equations given above can be slightly adapted in order to reduce the number of calculations. This is, however, not a major action and does also not contribute to the principles of the mechanism. Therefore, in order to keep this description free of unnecessary complexity, we omit to discuss this part and focus on the core of the mechanism which becomes always active when pallets leave or enter a store function (e.g., in a warehouse zone or on a truck).

When $k$ pallets of an SKU are taken from a store function (and immediately put to the next store function), the variables change on both sides. First, the store $\mathrm{CO}_{2}$ assignment has to be conducted as described above, as the number of pallets will now change and a new time interval $t$ needs to be started. This procedure can change the TAI figures on both sides. Then, a $\mathrm{CO}_{2}$ equivalent transfer is calculated as

$$
C E T=k T A E(S K U)
$$

Then, CET can be simply added at the recipient store function and subtracted at the delivering store function, leaving the total $\mathrm{CO}_{2}$ emission unchanged as required.

\subsection{Summarizing Data Model, Implementation and First Results}

In order to give an overview, we finally summarize the relevant entities of the simulation data model. The current data model has more than 60 external entities and a significant number of further entities that are only present during the simulation run. Figure 2 only addresses the entities introduced above and only the attributes directly relevant to the $\mathrm{CO}_{2}$ assessment; all other entities and attributes are left out.

Within the e-SAVE project, a data-driven simulation tool is under development based on SimChain and Plant Simulation. The tool includes a GUI that implements the parameters required for the $\mathrm{CO}_{2}$ assessment. A first implementation step has been completed in March 2013 and the resulting tool tested with original data from the project partner Barilla, scoping a large distribution relationship to a European state with the distribution source at Barilla's headquarter near Parma (Italy). Results show that the model seems to represent the real system adequately. However, also some systematic deviations could be detected, leading to current research on the reasons that are expected to be found in different approaches for the current LCA and the assumptions and mechanisms represented by the simulation data model. The implementation will be further refined and amended until spring 2014, with evaluations on additional scenarios.

\section{CONCLUSION AND OUTLOOK}

In this paper a detailed simulation model has been illustrated to reduce the $\mathrm{CO}_{2}$ impact of the FMCG distribution supply chain. The model allows for determining the results in an adequate accuracy and aggregation, based on a thorough requirements analysis. It is limited to transport and store functions (following the definition of Wieneke-Toutaoui 1987), but it provides a model for a data-driven simulation with a clear concept of emission allocation to provide suitable KPI.

There is still significant open research. First, the authors plan to extend the model to manufacture and assembly functions, in order to model actions like promotion packaging. While the approach to allocate the emission caused by warehouses, the emission from transports could obviously be more sophisticated. Also, the authors intend to investigate which kind of allocation measure (by pieces, volume, weight) is 
most adequate in which situation. This will be combined with a more intense comparison of the simulation results with the current calculations in practice.

\begin{tabular}{ll|l|} 
tempZones & \multicolumn{2}{l}{ temperature zones within a supply chain scenario } \\
\hline ID & Key \\
\hline \multirow{2}{*}{ warehouse } & warehouses in the supply chain \\
\hline ID & Primary Key \\
\hline EWO & Emission $\mathrm{kg} \mathrm{CO} /$ day \\
\hline \multirow{2}{*}{ Zone } & ID & Primary Key \\
\hline warehouseID & FK to warehouse \\
\hline tempZoneID & FK to tempZones \\
\hline EWZ & Emission $\mathrm{kg} \mathrm{CO}_{2} /$ day \\
\hline
\end{tabular}

sku type of storage units

\begin{tabular}{|l|l|}
\hline ID & Primary Key \\
\hline requTemp & FK to tempZones \\
\hline netWeight & in $\mathrm{kg} / \mathrm{SKU}$ \\
\hline grossWeight & in $\mathrm{kg} / \mathrm{SKU}$ \\
\hline Volume & in $\mathrm{m}^{3} / \mathrm{SKU}$ \\
\hline
\end{tabular}

meansOfTransport different categories of trucks, ships, etc.

\begin{tabular}{|l|l|}
\hline ID & Primary Key \\
\hline tempZone & FK to tempZones \\
\hline ETF & Emission full g / km \\
\hline ETE & Emission empty $\mathrm{g} / \mathrm{km}$ \\
\hline ETZ & Emission $\mathrm{kg} \mathrm{CO} /$ day for cooling (assuming only one zone) \\
\hline
\end{tabular}

runSKU

SKU during simulation runtime per zone

\begin{tabular}{|l|l|}
\hline refSKU & FK to SKU \\
\hline refZone & FK to zone (indirectly also identifies the warehouse) \\
\hline CNI & number of currently stored instances \\
\hline TAI & $\mathrm{CO}_{2}$ equivalent of the CNI instances in $\mathrm{kg}$ \\
\hline
\end{tabular}

Figure 2 Data model simplified to $\mathrm{CO}_{2}$ assessment aspects with entities and attributes (FK=Foreign Key).

\section{ACKKNOWLEDGEMENT}

This work is partially based on the "Energy Efficiency in the Supply Chain through Collaboration, Advanced Decision Support and Automatic Sensing" (e-SAVE) project (FP7 288585), which is funded by European Commission under the 7th Framework programme, ICT (Information and Communication Technologies).

\section{REFERENCES}

Alicke, K., and K. Gutenschwager. 2004. "Supply Chain Simulation mit ICON-SimChain”. In Logistik Management, edited by H. Kopfer, T. Spengler, and S. Voß, 161-178. Physica, Heidelberg.

Andersson, J., A. Skoogh and B. Johansson. 2012. "Evaluation of methods used for life-cycle assessments in discrete event simulation", In Proceedings of the 2012 Winter Simulation Conference, edited by C. 
Rabe, Gutenschwager, Fechteler, and Sari

Laroque, J. Himmelspach, R. Pasupathy, O. Rose, and A.M. Uhrmacher. Piscataway, New Jersey: IEEE.

Archibald, G., N. Karabakal, and P. Karlsson. 1999. "Supply Chain vs. Supply Chain: Using Simulation to Compete Beyond the Four Walls". In Proceedings of the 1999 Winter Simulation Conference, editors P.A. Farrington, H.B. Nembhard, D.T. Sturrock, and G.W. Evans, 1207-1214. Piscataway, New Jersey: IEEE.

Bagchi, S., S.J. Buckley, M. Ettl, and G.Y. Lin. 1998. "Experience using the IBM Supply Chain Simulator". In Proceedings of the 1998 Winter Simulation Conference, editors D.J. Medeiros, E.F. Watson, J.S. Carson, and M.S. Manivannan, 1387-1394. Piscataway, New Jersey: IEEE.

Baumgärtel, H., T. Stäblein, and J. Wilke. 2007. "The Supply net simulator SNS: An artificial intelligence approach for highly efficient supply network simulation". In Management logistischer Netzwerke, edited by H.-O. Günther, D.C. Mattfeld, and L. Suhl, L., 85-110. Physica, Heidelberg.

Boulonne, A., B. Johansson, A. Skoogh and M. Aufenander. 2010. "Simulation data architecture for sustainable development", In Proceedings of the 2010 Winter Simulation Conference, edited by B. Johansson, S. Jain, J. Montoya-Torres, J. Hugan, and E. Yücesan. Piscataway, New Jersey: IEEE.

Che, Z.H. 2010. "Using fuzzy analytic hierarchy process and particle swarm optimisation for balanced and defective supply chain problems considering WEEE/RoHS directives" 48(11) 3355-3381.

Cirullies, J., C. Schwede, and M. Toth. 2012. "Intra-simulative ecological assessment of logistics networks: benefits, concepts, and tool enhancement", In Proceedings of the 2012 Winter Simulation Conference, edited by C. Laroque, J. Himmelspach, R. Pasupathy, O. Rose, and A.M. Uhrmacher. Piscataway, New Jersey: IEEE.

European Parliament. 2003a. "Directive 2002/96/EC of the European Parliament and of the Council of 27 January 2003 on waste electrical and electronic equipment (WEEE)". Official Journal of the European Union,24-38.

European Parliament. 2003b. "Directive 2002/95/EC of the European Parliament and of the Council of 27 January 2003 on the restriction of the use of certain hazardous substances in electrical and electronic equipment". Official Journal of the European Union, 9-23.

Finkbeiner, M., R. Hoffmann, K. Ruhland, D. Liebhart and B. Stark. 2006. "Application of Life Cycle Assessment for the Environmental Certificate of the Mercedes-Benz S-Class". International Journal of Life Cycle Assessment 11 (4): 240-246.

Gao, Y., J. Li, and Y. Song. 2009. "Performance evaluation of green supply chain management based on membership conversion algorithm". In Proceedings of ISECS International Colloquium on Computing, Communication, Control, and Management. Sanya, China, 237-240.

Gorree, M., J.B. Guinée, G. Huppes, and L. van Oers. 2000. Environmental Life Cycle Assessment of Linoleum. Final Report, Centre of Environmental Science, Leiden University (CML-UL).

Gross, W.F., C. Hayden, and C. Butz. 2012. "About the impact of rising oil price on logistics networks and transportation greenhouse gas emission". Logistics Research 4 (3-4), 147-156.

Hausberger, S., M. Rexeis, M. Zallinger, and R. Luz. 2009. "Emission Factors from the Model PHEM for the HBEFA Version 3". Graz University of Technology: Report Nr. I-20/2009. Haus-Em 33/08/679.

International Standards Organisation (ISO). 2009a. Environmental management - Life cycle assessment Principles and framework (ISO 14040:2006). Beuth, Berlin.

International Standards Organisation (ISO). 2009b. Environmental management systems - Requirements with guidance for use (ISO 14001:2009). Beuth, Berlin.

Kuhl, M. E., Zhou, X. 2009. Sustainability Toolkit for Simulation-based Logistics Decisions. In Proceedings of the 2009 Winter Simulation Conference, edited by M.D. Rossetti, R.R. Hill, B. Johansson, A. Dunkin, and R.G. Ingalls, p. 1466 - 1473. Piscataway, New Jersey: IEEE.

Lindskog, E., L. Lundh, J. Berglund, Y.T. Lee, A. Skoogh, and B. Johansson. 2011. "A method for determining the environmental footprint of industrial products using simulation", In Proceedings of the 
2011 Winter Simulation Conference, edited by S. Jain, R.R. Creasey, J. Himmelspach, K.P. White, and M. Fu., 2136-2147. Piscataway, New Jersey: IEEE.

Miller, J.G., and T.E. Vollman. 1985. "The hidden factory". In Harvard Business Review September/October 1985, 142-150.

Rabe, M., and M. Deininger. 2011. "State of art and research demands for simulation modeling of green supply chains". International Journal of Automation Technology 6 (3) 296-303.

Rabe, M., and P. Gocev. 2006. "Simulation Models for Factory Planning through Connection of ERP and MES Systems". In Simulation in Produktion und Logistik 2006, edited by S. Wenzel, 223-232. Erlangen: SCS Publishing House.

Ruini, L. 2012. “Implementing EPD Process Certification: What's done \& what's next?" Slide presentation at EPD Conference, Stockholm 2012/05/15. http:/www.environdec.com/PageFiles/901/ Implementing EPD Process Certification - Luca Ruini Barilla.pdf [Accessed 25.05.2013].

Seliger, G., B. Wieneke-Toutaoui, and M. Rabe. 1987. "Integrated Modelling of Manufacturing Systems for Planning Purposes". In Intelligent and Integrated Manufacturing Analyses and Synthesis, edited by C.R. Liu, A. Requicha, and S. Chandrasekar, 405-416. ASME, Boston.

Widok, A.H., L. Schiemann, P. Jahr, and V. Wohlgemuth. 2012. "Achieving sustainability through a combination of LCA and DES integrated in a simulation software for production processes", In Proceedings of the 2012 Winter Simulation Conference, edited by C. Laroque, J. Himmelspach, R. Pasupathy, O. Rose, and A.M. Uhrmacher. Piscataway, New Jersey: IEEE.

Wieneke-Toutaoui, B. 1987. Rechnerunterstütztes Planungssystem zur Auslegung von Fertigungsanlagen. Hanser, München, Wien.

\section{AUTHOR BIOGRAPHIES}

MARKUS RABE is full professor for IT in production and logistics at the Technical University Dortmund. Until 2010 he had been with Fraunhofer IPK in Berlin as head of the corporate logistics and processes department and member of the institute direction circle. His research focus is on information systems for supply chains, production planning and simulation. Markus Rabe is vice chair of the "Simulation in Production and Logistics" group of the simulation society ASIM, member of the editorial board of the Journal of Simulation, member of several conference program committees, has chaired the ASIM SPL conference in 1998, 2000, 2004, and 2008, and is local chair of the WSC'2012 in Berlin. More than 150 publications and editions report from his work. His e-mail address is markus.rabe@tu-dortmund.de.

KAI GUTENSCHWAGER studied Business Informatics and received his doctoral degree from the Technical University of Braunschweig. He worked for SimPlan as a head of the office being a simulation expert in the field of logistics and supply chain management. From 2009 he was a professor for information systems in logistics at Ulm University of Applied Sciences and since 2013 he is a professor at Ostfalia University of Applied Sciences. His research is focused on IT-based methods for the simulation and optimization of production and logistics systems. His e-mail address is k.gutenschwager@ostfalia.de.

TILL FECHTELER is Branch Manager at SimPlan AG, Braunschweig, Germany, mainly working as a senior consultant and project manager in simulation projects. Since 1997, he has been participating in more than 100 simulation projects for several industries. His e-mail address is till.fechteler@simplan.de.

MEHMET UMUT SARI is a research assistant at the Technical University Dortmund, department IT in Production and Logistics, since 2012. He studied Industrial Engineering at the Technical University Dortmund and graduated with a thesis on technology-oriented competition analysis of manufacturers in the wind energy industry. His research focus is energy management in supply chains. His e-mail address is umut.sari@tu-dortmund.de. 